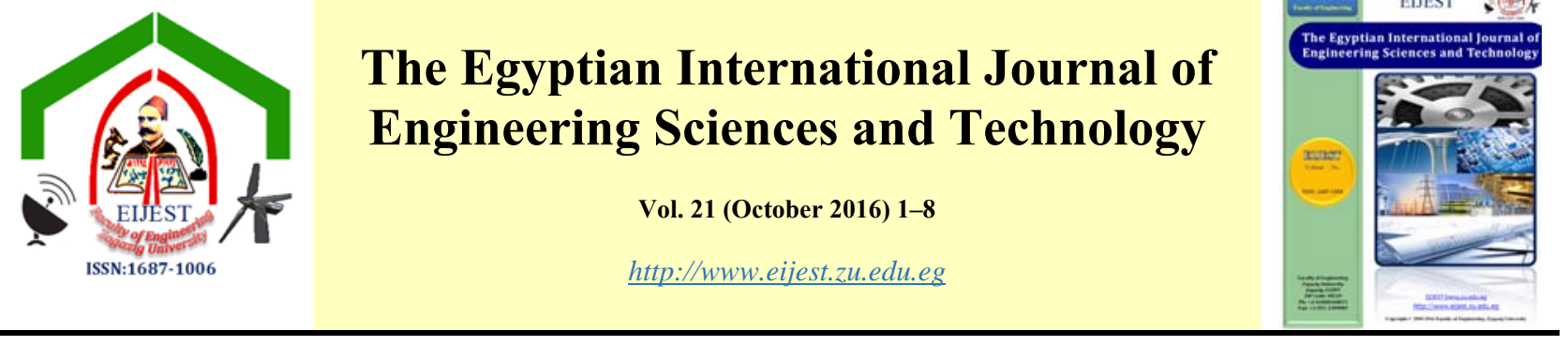

\title{
Mechanical Properties, Microstructure and Wear Resistance of Recycled Poly-propylene Filled with Iron Powder
}

\author{
Ayman M. M. Abdelhaleem* \\ Mechanical Design and Production Engineering Department, Faculty of Engineering, \\ Zagazig University, Zagazig, Sharkia, Egypt, P.O. Box 44519
}

\begin{tabular}{l}
\hline A R T I C L E I N F O \\
\hline Article history: \\
Received: 26 April 2016 \\
Received in revised form: 29 \\
May 2016 \\
Accepted: 3 June 2016 \\
Available online: 14 July \\
2016 \\
\hline
\end{tabular}

Keywords:

Polypropylene;

iron particles;

Injection moulding

process;

Mechanical

properties;

Wears resistance

\begin{abstract}
A B S T RAC T
The main objective of this research is to study the effect of adding iron powder (IP) to recycled polypropylene (RPP) using the injection moulding process. The iron powder was mixed mechanically with RPP in $10 \%, 20 \%$, and $30 \%$ by weight. The mechanical properties of recycled polypropylene reinforced with iron powder were investigated using tensile, and hardness tests. The wear resistance of the composites were investigated. The results showed that, by adding $10 \%, 20 \%, 30 \%$ wt. of iron powder to the recycled polypropylene, the ultimate tensile strength increased from $21 \mathrm{~N} / \mathrm{mm}^{2}$ for neat recycled polypropylene to $24.828 \mathrm{~N} / \mathrm{mm}^{2}$ (i.e. $18.23 \%$ ), 26.34 $\mathrm{N} / \mathrm{mm}^{2}$ (i.e. $25.44 \%$ ), $27.72 \mathrm{~N} / \mathrm{mm}^{2}$ (i.e. $32 \%$ ), respectively. The modulus of elasticity is increased to $412.06 \mathrm{MPa}(6.28 \%), 427.4 \mathrm{MPa}(10.259 \%$, and to 566.30 $\mathrm{MPa}(46.09 \%)$ when adding 10\% IP, $20 \%$ IP, and 30\% IP to the RPP respectively. The hardness test results, using Shore D tester, showed that, as the iron particles contents are increased, the hardness are increased from 71 for the RPP, to $72.5,75$, and 76 for RPP with iron particles contents of $10 \%, 20 \%$, and $30 \%$ wt respectively. The wear test results showed that, the weight loss is decreased at $10 \%, 20 \%$, and $30 \%$ of iron powder in the recycle polypropylene when compared with the neat recycle polypropylene by $43.34 \%, 21.98 \%$, and $18.28 \%$ respectively. Scan Electronic Microscopy (SEM), showed that, a good interlock and interference between the iron particles and the recycled polypropylene.
\end{abstract}

\section{Introduction}

Polypropylene (PP) is widely used in many areas, especially in automotive and machinery and small equipment. It is possible for many items of the mechanical parts to replace metal parts by other pieces of plastic and keep similar characteristics [1]. Since, pure plastic is expensive, and the recycled plastic is less expensive than that of pure plastic, the plastic manufactures tend to use the recycled plastic material. Therefore, most of the plastic factories have a system to collect and reuse of the damaged plastics

\footnotetext{
* Corresponding author. Tel.: +2-010-0656-5423.

E-mail address: aymanmns@hotmail.com.
} 
products, the finished purpose plastic products, and the product plastic flashes, and runners.

Although the plastic containers used for Foodstuff and Medicals are prevents to be used again for the same purpose, it may be used again and again for other industries such as auto parts, electrical appliances, child toys, and home parts such as cheers, tables, ....etc.

Loredana Incarnato, et al [2] studied the rheological and mechanical properties of recycled polypropylene RPP, they concluded that it is possible to add a high percentage $70 \% \mathrm{w} / \mathrm{wt}$ of RPP without a significant reduction in the mechanical performance of the polypropylene film.

JL. Acosta, et al [3] presented results studying conducting composites based on low density polyethylene, polypropylene and a mixture of two conducting fillers one was the carbon black (CB) and the other was iron particles $(\mathrm{Fe})$ in different concentrations and with a total filler percentage up to $50 \%$. They concluded that, the mechanical strength of the polymer composites is improved by the presence of both fillers $(\mathrm{Fe}+\mathrm{CB})$.

M. Nikzad et al [4] explained the development and characterization of an iron-filled the Fused Deposition Modelling grade Acrylonitrile Butadiene Styrene (ABS) composite material for direct Fused Deposition Modelling processing without the need of binder removal or infiltration process. The flexible filaments of the new material have been successfully produced. They compared the dynamic mechanical test values and heat capacity values for the virgin ABS and the new composite materials. They concluded that a great improvement of the properties of the new composite.

Munir Tasdemir and H. Ozkan Gulsoy [5] studied the mechanical properties of metal-polymer matrix composites experimentally. High density polyethylene (HDPE), polypropylene (PP), and polystyrene were used as the polymer matrix and $\mathrm{Fe}$ powder in 5, 10, and $15 \mathrm{vol} \%$ was used as the reinforcement. They concluded that vol $\%$ Fe reduced the Izod impact strength of HDPE much more than that of PP and PS, while Fe powder increased the hardness of HDPE more than that of PP and PS. Among the composites, PS-Fe composites had higher yield, tensile strength and modulus of elasticity than HDPE-Fe and PP-Fe composites.

X. L. Chen, et al [6] The effects of iron powder as a synergistic agent on the flame retardancy of intumescent flame retardant PP composites were studied. They showed that, a suitable amount of $\mathrm{Fe}$ plays a good effect in the flame retardancy of intumescent flame retardant PP composites.
Tan Foo Khoon, et al [7] studied the composite polymer with the addition of metal powder to improve the mechanical properties, thermal and electrical and optical and pharmaceutical properties as compared with pure polymer. Different combinations of $\mathrm{Ni0} .2 \mathrm{Zn} 0.8 \mathrm{Fe} 2 \mathrm{O} 4$ (NZF) and $\mathrm{PP}$ are used. They found that, with the increase in the percentage of the NZF $\mathrm{wt} \%$, the dielectric properties are increased of the composite. Also they showed that, the incorporation of ceramic filler improves the dielectric constant and dielectric loss increase of the composite correspondingly increases the potential use as an absorbing material for electromagnetic waves. M. Nikzad, et al [8] introduced an investigation on thermal and mechanical properties of new metalparticle filled ABS composites for applications in Fused Deposition Modelling rapid prototyping process. They found that, significant improvements of ABS thermal and mechanical properties due to metallic fillers can potentially high performance and functional prototypes on the existing Fused Deposition Modelling platform for a wide range of applications.

Segun Mathew Adedayo et al [9] produced Iron ore tailings filled PP composites using the compoindirect squeeze casting process. Particle sizes 150, 212 and $300 \mu \mathrm{m}$ where considered for different volume fractions of $5 \%$ to $30 \%$ at intervals of $5 \%$. The experimental results show that elongation at break for iron ore tailings filled PP reduces with increasing $150 \mu \mathrm{m}$ particle sizes. Tensile strength reduces with increasing filler.

M.A. Onitiri and S.M. Adedayo [10] produced iron ore tailings reinforced PP composites from conventional compo-casting and a proposed compoindirect squeeze casting processes. Their study aims to provide useful information on possibility of the use of iron ore tailings reinforced PP for compressive applications which will culminate to judicious use of iron ore tailings that is been piled up as waste material at the iron ore beneficiation sites. PP cast produced using the compo-indirect squeeze casting (C-ISC) process exhibited better compressive strength and Young's modulus of about 12 and 4.5 $\%$, respectively, while a decreasing of $9.2 \%$ in yield strength was recorded. ITR-PPCs with $150 \mu \mathrm{m}$ fillers produced from C-ISC process have lower yield stress, compressive strength and Young's modulus at volume contents above $10 \%$. It also exhibited lower strain at fracture at volume content above $15 \%$, while composites filled with 212 - and $300 \mu \mathrm{m}$ particle size iron ore tailings using the C-ISC process had better strain at fracture.

Alaa A. et al [11] studied a polymer composite using polyester polymer with iron weave wire ratios $(5 \%$, 
$10 \%, 15 \%, 20 \%)$. Their results showed that an improvement in the mechanical properties after reinforcement by metals. And the value of mechanical properties is increased with increasing percentage of reinforcement.

N. Sa'ude et al [12] present the development of a new polymer matrix composite material for use in injection moulding machine. The material consists of iron powder filled in an ABS and surfactant powder material. They found that, the increasing of the vol. $\%$ of the iron filler will increase the hardness, tensile and flexural strength.

The main aim of the present work is to investigate the effect of adding of the Iron powder (IP) into the RPP on the mechanical properties, wear resistance, and microstructure using injection moulding process.

\section{Experimental work}

\subsection{Materials and Specification}

RPP was supplied from Egyptian market as shown in Figure 1(a). The well-known burn test was operated on the RPP to know it $[13,14]$. The burn test result of the RPP was (1) colour of the flame was yellow, (2) it was drips, (3) colour of the flame when continuous burning was blue and yellow tips, (4) smell was phenol, and (5) the speed of the burning was slow (6) float in water. The density of the neat $\mathrm{RPP}$ is $0.92 \mathrm{~g} / \mathrm{cm}^{3}$, and the densities of the composite $\mathrm{RPP} / \mathrm{IP}$ are $1.625 \mathrm{~g} / \mathrm{cm}^{3}, 2.31 \mathrm{~g} / \mathrm{cm}^{3}$, and $3.0 \mathrm{~g} / \mathrm{cm}^{3}$ when adding $10 \%, 20 \%$, and $30 \%$ wt respectively of IP into RPP.

Since, Grinding can be used for powder manufacture whenever a material is brittle enough so that it can be broken into finer particles [15]. Iron chip has been collected as iron output of factories working in the manufacture and grinding engine liner. The iron chips were gray cast iron which is widely used for cylinder liner [16]. The following treatment was operated on the iron chip to obtain the iron powder:

1. Washing of the iron chips well and filtered by any suspended substances

2. Iron chips was good washing with a solution of dilute hydrochloric and so to remove any rust or oxidize

3. Iron chips were rinse well with clean water several times to get rid of any stuck rusts

4. Iron chips were drying in an oven at a temperature of 100 degrees to evaporate any existing water to remove any moisture from it.

5. After drying the iron chips directly, it were wash gasoline for not given a chance to oxidize

6. Sift the work of the iron chips to extract iron powder using a sieve of 80 mesh and was approximately output from each $1 \mathrm{~kg}$ of iron chips give $50 \mathrm{~g}$ iron powder. The IP produced by the process have irregular shapes.

7. The produced IP, Figure 1 (b) was kept in a plastic bag and close it well placed so as not to be oxidized and ready for use

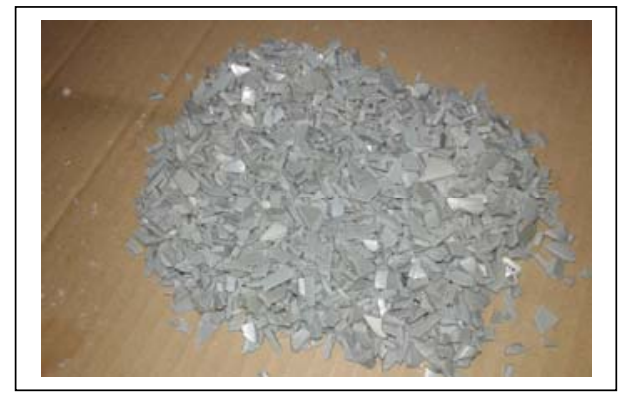

(a) RPP

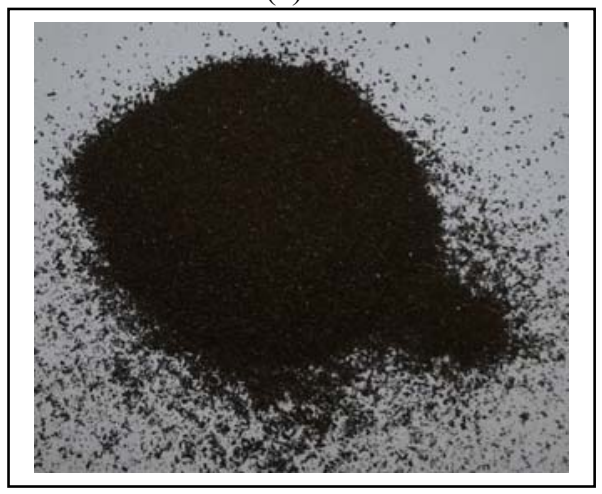

(b) IP

Figure 1 shows photo pictures of the RPP and the IP

\subsection{The mould}

Plastic injection mould for tensile and wear test samples was designed and manufactured from steel material. The mould is checked many times to be suitable for producing the required test samples according to ASTM638 [17]. In this mould, direction of the flow of the plastic takes in account that it was in one direction for each sample to avoid any probability of occurring of weld lines which may cause weakness and hence cracking.

\subsection{Machines and Processing for Manufacturing}

To produce the test samples the plastic injection mould is mounted into an injection moulding machine (HAITIAN PL1200), i.e. type maximum clamping force $1200 \mathrm{KN}$. The barrel temperature profile along the injection-moulding machine is adjusted to be $140,160,180,190$ and 200 ${ }^{\circ} \mathrm{C}$. The barrel temperature is re-adjusted during the process when adding RPP with IP composite according to the requirements for the injection process. Table-1 shows the operating conditions of the machine to manufacture the test specimens. 
The process may be described as follow:

First: the IP is dried again using a dryer for $30 \mathrm{~min}$ at $120 \mathrm{C}^{\circ}$ to avoid possible moisture.

Secondly: RPP was dried at $80 \mathrm{C}$ for $2 \mathrm{~h}$ in an air dryer before processing to avoid possible moisture degradation reactions.

Thirdly: RPP was mechanically mixed with $(10 \%$, $20 \%, 30 \%$, ) wt of IP.

Fourth: feeding the extruder of injection moulding machine (single screw extruder) by the mixed composites to produce the primary test samples.

Fifth: the produced primary test samples with its sprue and runners are crushed in a crusher forming small pellets with identical sizes.

Six: the shredded particle is fed into the injection moulding machine again to produce the final test samples. The main reason behind these stages is to obtain good distribution of the IP in the RPP.

Table 1: Operating conditions of the injection moulding machine

\begin{tabular}{|c|c|c|c|c|c|}
\hline $\begin{array}{l}\text { Parameter } \\
\text { pressure in } \\
\text { (Bar) }\end{array}$ & 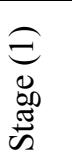 & 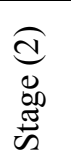 & 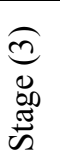 & 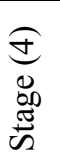 & 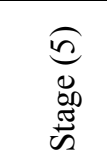 \\
\hline Charging & 40 & 40 & 40 & 40 & 40 \\
\hline Closing & 40 & 40 & 50 & 50 & 70 \\
\hline Injection & 100 & 100 & 90 & 80 & 80 \\
\hline Holding & & & & & 100 \\
\hline Cooling & & & & & holding \\
\hline Opening & 50 & 50 & 50 & 50 & 50 \\
\hline Ejection & 30 & 30 & 30 & 30 & 30 \\
\hline
\end{tabular}

The tensile and wear test samples as shown in Figure 2 obtained from injection moulding were used to study mechanical properties, wear resistance and microstructure.

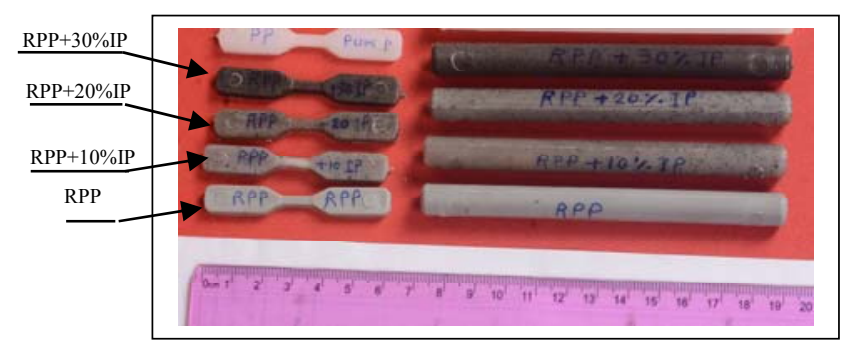

Figure 2 shows the photo of the real tensile test samples according to ASTM D638 and wear test samples

\subsection{Testing}

The tensile test were carried out using LLOYD tensile testing machine (The model: LRX plus) at a cross-head speed of $5 \mathrm{~mm} / \mathrm{min}$ at room temperature, three tensile specimens were tested for each reported value and take the average value. Hardness test was carried out by Duremeter shore D according to ASTM D2240 at room temperature. Six points of specimen were investigated and reported the average value. A pin on disc is used to carry out wear resistance. All samples are pressed against a rotating disc with surface roughness of (P1000) at room temperature, with rotating disc speed of $57 \mathrm{rpm}$. The rotating disc serves as a counter face and the stationery block serves as the test specimen. At distance of $(10 \mathrm{~m}, 25 \mathrm{~m}$, and $50 \mathrm{~m})$, weight loss were measured for each sample at variety of loads $(500 \mathrm{~g}$, $1000 \mathrm{~g}$, and $1500 \mathrm{~g}$ ) by using a digital balance with accuracy $10^{-3}$ before and after the test. Microstructure was studied using SEM (Bruker type)

\section{Results and Discussion}

\subsection{Results of the tensile test}

Three samples of each of the required compositions to tested are generated, RPP, and RPP with different IP contents of ratios, $10 \%, 20 \%$, and $30 \%$ wt. The average values of the results were obtained and introduced in Figure 3. The ultimate tensile strength for each composition is listed in Table 2. From Figure 3, it can be noticed that, by increasing the IP percentage, the ultimate tensile strength is improved according to the following discussions. When adding $10 \%$ IP to the RPP, the ultimate tensile strength is increased to $24.828 \mathrm{MPa}$ (19\%), and when adding $20 \%$ IP to the RPP, the ultimate tensile strength is increased to $26.344 \mathrm{MPa}$ (26.1\%), and when adding $30 \%$ IP to the RPP, the ultimate tensile strength is increased to $27.72 \mathrm{MPa}$ $(32 \%)$. From the above results, it may be concluded that, as the IP is increased in the RPP matrix, the ultimate tensile strength is increased. From the data of Figure 3, the modulus of elasticity is calculated for the RPP and for the RPP/IP for different composite $[18,19]$. And it is found that, the modulus of elasticity is increased from $387.63 \mathrm{MPa}$ to $412.06 \mathrm{MPa}$ $(6.28 \%), 427.4 \mathrm{MPa}(10.259 \%)$, and to 566.3025 (46.09\%) when adding 10\% IP to the RPP, 20\% IP to the RPP, and $30 \%$ wt IP to the RPP respectively.

The increasing of the ultimate tensile strength of the RPP/IP was due to the existing of the IP with irregular shapes in the RPP matrix and the high injection and holding pressure during injection process that made good contact, and good interlocking between the RPP and the IP.

It can be concluded from Figure 3 that, the presence of IP reinforcement in the RPP matrix raises the composite strength and the modulus of elasticity. Therefore, the effect of adding of the IP into the polymeric on the tensile properties of the composites is of particular interest for special jobs like plastic 
magnetics goods (mobile telephone covers, fused deposition modelling) [2-11].

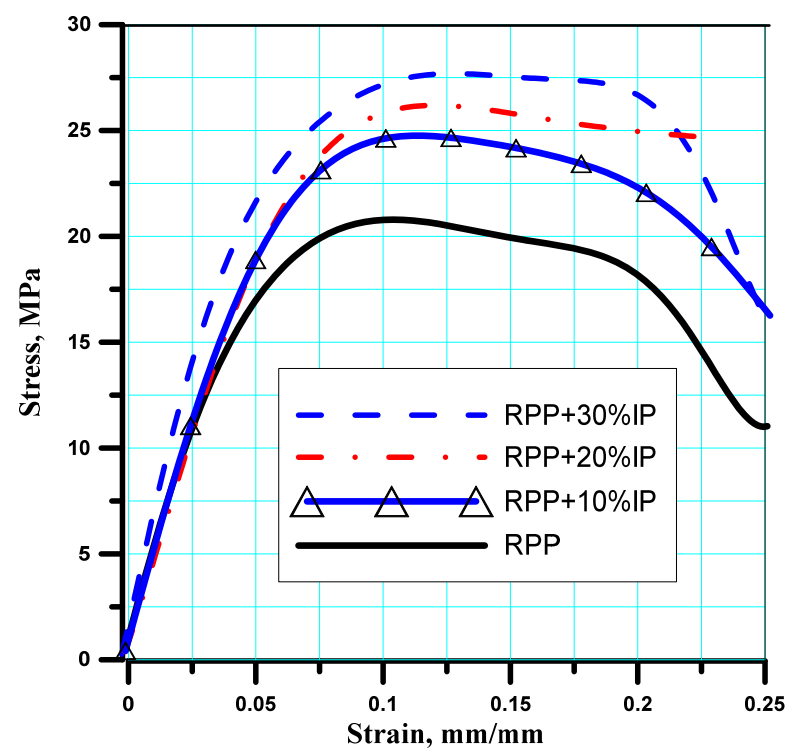

Figure 3, Stress strain curve of RPP with different amount of IP.

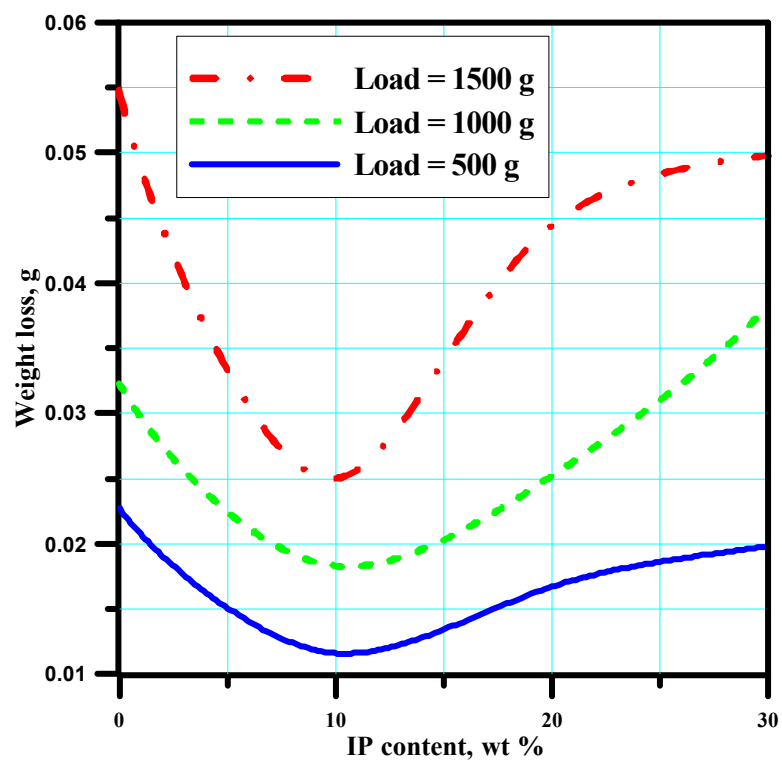

Figure 4 show the effect of adding IP into the RPP on the weight loss for $500 \mathrm{~g}, 1000 \mathrm{~g}$, and $1500 \mathrm{~g}$ at $25 \mathrm{~m}$ travelling distance and speed of $34 \mathrm{~mm} / \mathrm{s}$.

However, the increasing of the UTS of the RPP with the IP, and the advantages of the magnetism and the conductivity, the process complexity, the increasing in the weight of the products which is main problem, and also cost must be taken into consideration.
Table 2 shows the ultimate tensile strength for each composition

\begin{tabular}{ccl}
\hline $\begin{array}{l}\text { Description } \\
\text { Composition }\end{array}$ & $\begin{array}{l}\text { Ultimate } \\
\text { Tensile } \\
\text { strength, MPa }\end{array}$ & $\begin{array}{l}\text { Modulus of } \\
\text { Elasticity, } \\
\text { MPa }\end{array}$ \\
\hline RPP & 21 & 387.63 \\
\hline RPP + 10\% IP & 24.828 & 412.06 \\
\hline RPP + 20\% IP & 26.344 & 427.40 \\
\hline RPP + 30\% IP & 27.722 & 566.30 \\
\hline
\end{tabular}

\subsection{The Results of Wear Test:}

The weight loss are calculated using pin on disc method, for each sample at travelling distance $25 \mathrm{~m}$ when applying loads of 500g, $1000 \mathrm{~g}$, and $1500 \mathrm{~g}$.

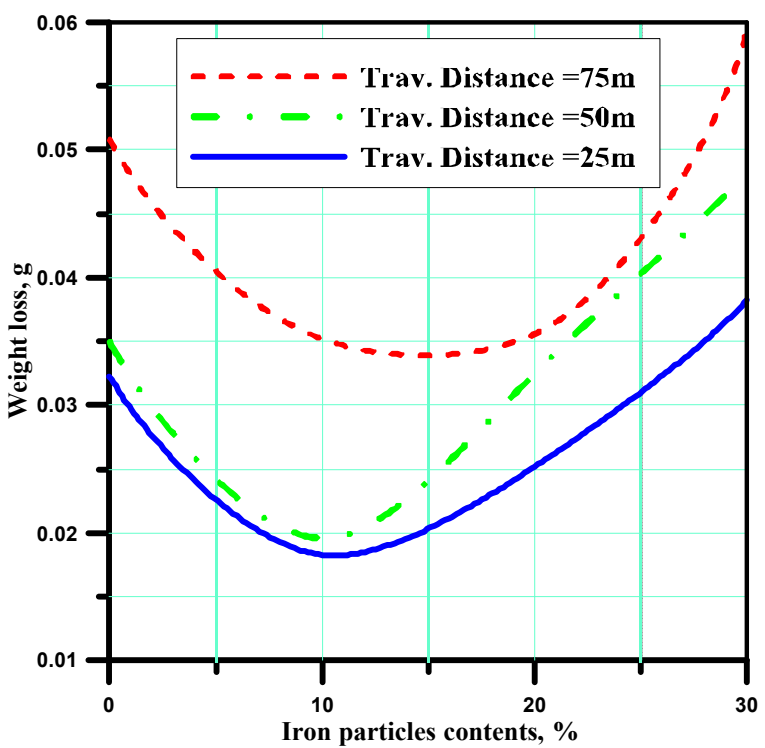

Figure 5 show the effect of adding of the IP into the RPP for travelling distances of $25 \mathrm{~m}, 50 \mathrm{~m}$, and $75 \mathrm{~m}$ when applying a load of $1000 \mathrm{~g}$ with speed of $34 \mathrm{~mm} / \mathrm{s}$.

From Figure 4 when applying a load of $500 \mathrm{~g}$, it can be observed that, the weight loss decreased at $10 \%, 20 \%$, and $30 \%$ for IP filling RPP when compared with the neat RPP by $48.9 \%, 26.4 \%$, and $12.77 \%$ respectively. When applying a load of $1000 \mathrm{~g}$, the weight loss is decreased at $10 \%, 20 \%$, and $30 \%$ of IP when compared with the neat RPP by $43.34 \%, 21.98 \%$, and $18.28 \%$ respectively. When applying a load of $1500 \mathrm{~g}$, the weight loss is decreased at $10 \%$ and $20 \%$ IP by $54.37 \%, 18.97 \%$ respectively, and gradually decreased for $30 \%$ $(9.12 \%)$ of IP when compared with the neat RPP. It can be concluded that, the best obtained results is for $10 \%$ IP in all of the contents in the RPP. For all of the applied load, the ratio of $30 \%$ is the worst obtained results because of, for higher contents of the IP, the composition abrasive itself and the IP was separated from the composite and became outside 
between the composite and the grinding surface, therefore it speed up the wear rate.

From Figure 5 when applying a load of $1000 \mathrm{~g}$ and at speed of $\mathrm{V}=34 \mathrm{~mm} / \mathrm{s}$, and for travelling distance of $25 \mathrm{~m}$, it is observed that, the weight loss decreased at $10 \%$, and $20 \%$ of IP in the RPP when compared with the neat RPP by $43.34 \%$ and $21.98 \%$. On the other hand at 30\% IP in the RPP, the wear loss is increased and the wear rate is increased by $18.4 \%$. For travelling distance of $50 \mathrm{~m}$, it is observed that, the weight loss decreased at $10 \%$, and $20 \%$ IP when compared with the neat RPP by $44 \%$ and $7.14 \%$. On the other hand at $30 \% \mathrm{IP}$, the wear loss is increased and the wear rate is increased by $37.71 \%$. For travelling distance of $75 \mathrm{~m}$, it is observed that, the weight loss decreased at $10 \%$, and $20 \%$ IP when compared with the neat RPP by $30.7 \%$ and $29.92 \%$. On the other hand at $30 \% \mathrm{IP}$, the wear loss is increased and the wear rate is increased by $17.32 \%$.

From the above discussion it can be concluded that, the best obtained results are at $10 \%$ IP in the RPP for both $25 \mathrm{~m}$ and $50 \mathrm{~m}$ travelling distances, and at $15 \% \mathrm{IP}$ in the RPP for $75 \mathrm{~m}$ travelling distances.

\subsection{The Result of Hardness Test}

The hardness is measured using shore D, Durometer and shown in Table 3. From these results it can be noted that the hardness of the neat RPP has 71 . When adding $10 \%$ IP with the RPP, the hardness increased to 72.5 which is $2.1 \%$. When adding $20 \%$ IP with the RPP, the hardness become 75 (5.63\%). When adding $30 \%$ IP with the RPP, the hardness is increased to 76 $(7.03 \%)$. Generally, as the IP in the RPP is increased, the hardness is increased.

Table 3 Hardness of the used materials

\begin{tabular}{ll} 
Materials & Hardness \\
\hline RPP & 71 \\
\hline RPP $+10 \%$ IP & 72.5 \\
\hline RPP $+20 \%$ IP & 75 \\
\hline RPP $+30 \%$ IP & 76 \\
\hline
\end{tabular}

\section{Microstructure of RPP/IP Composite}

SEM was used for scanning the composite at different combinations $10 \%, 20 \%$ and $30 \%$ wt, of the IP in the RPP. In Figure $6 \mathrm{a}, \mathrm{b}$, and $\mathrm{c}$ and at a concentration of $10 \%$ IP in the RPP, it can be seen that the distribution of the IP was good inside the RPP.
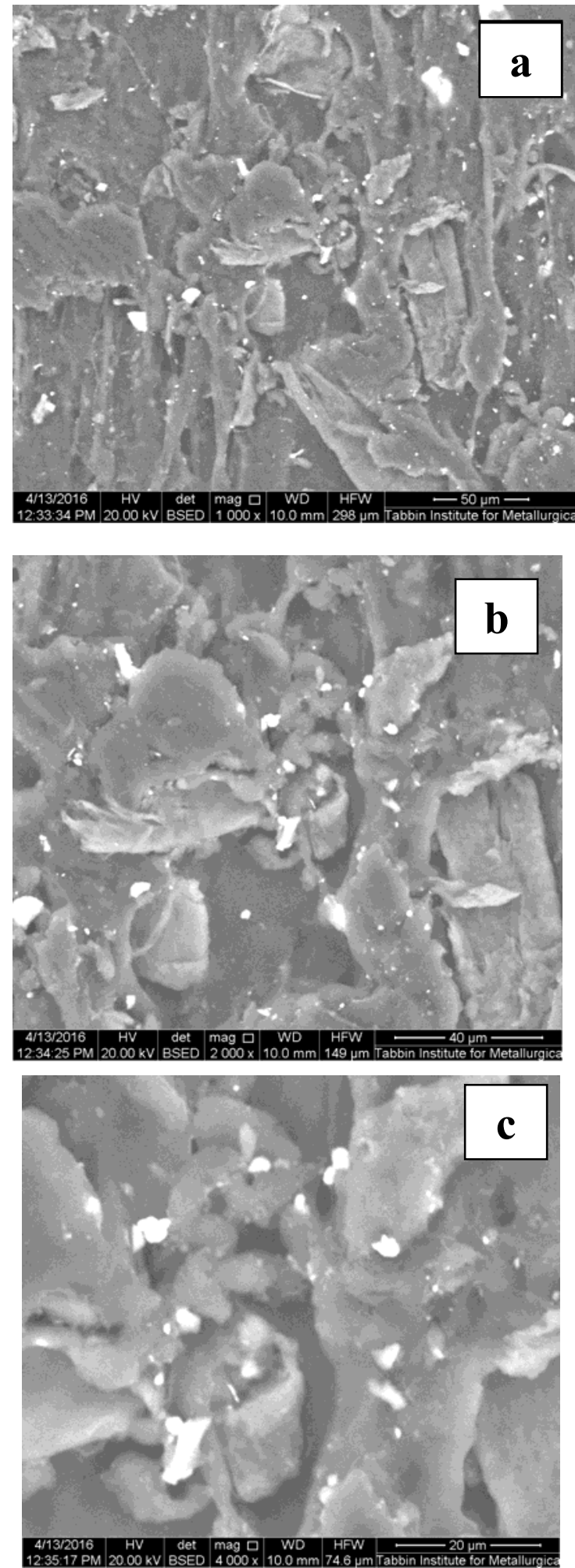

Figure 6 SEM of the RPP with 10\% IP

In Figure $7 \mathrm{a}$ and $\mathrm{d}$, it is shown that the extent of overlap of IP in the RPP. The irregular shapes of the 
IP led to good interference among IP and the RPP. In Figure $7 b$, at a concentration of $30 \%$ IP in the RPP, it can be noticed that the IP are well distributed among the RPP as shown in figure 7-a. The improving of the mechanical properties of the RPP/IP is due to the irregular shapes of the IP.
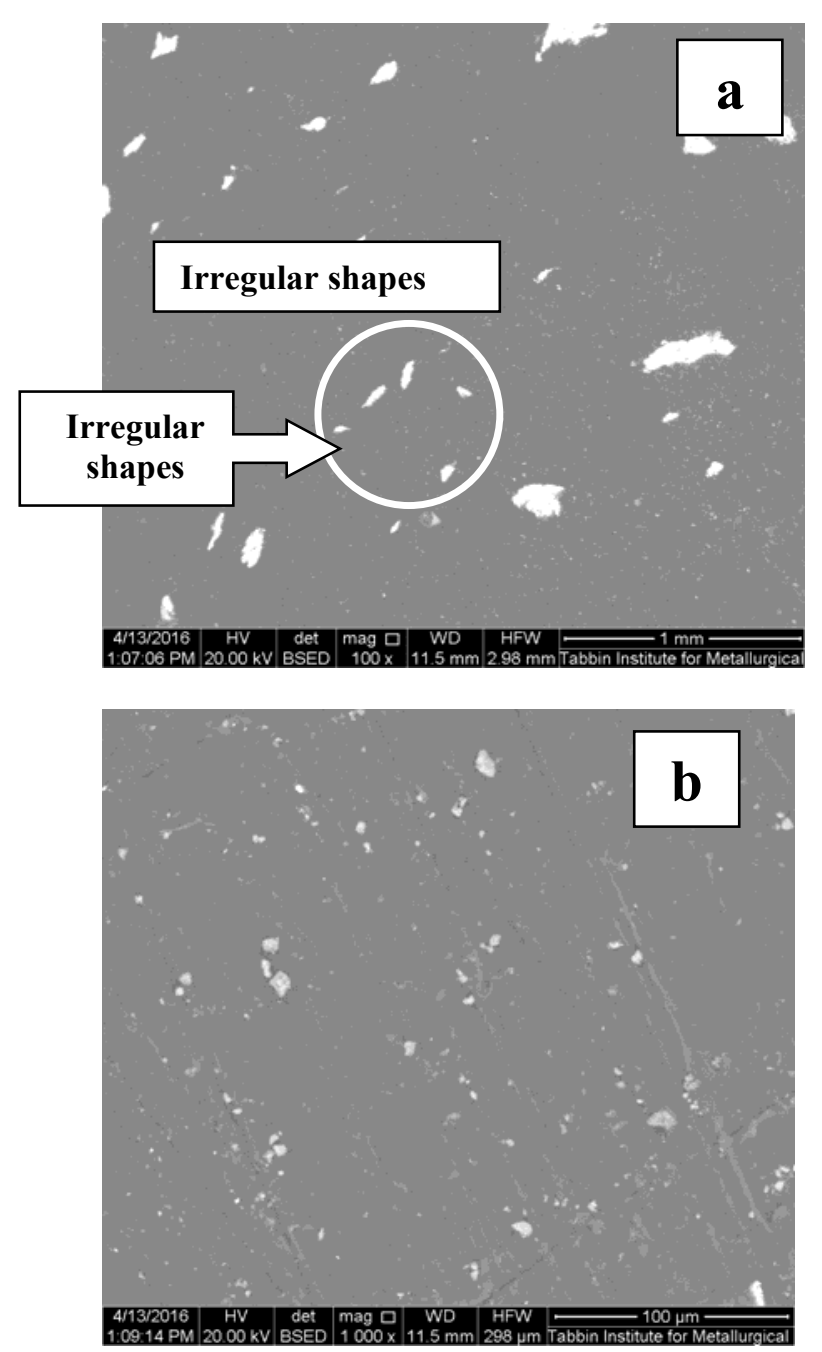

Figure 7 SEM of the RPP with $30 \%$ IP

\section{Energy Dispersive Spectroscopy (EDS)}

Energy Dispersive Spectroscopy (EDS) is used to find what elements are present in the composite. Figure 8-a shows good distribution of the IP in the RPP, and Figure 8-b shows a good description of the existing elements in the RPP with $30 \% \mathrm{IP}$ and the clear existing of the IP (Fe) in the RPP.

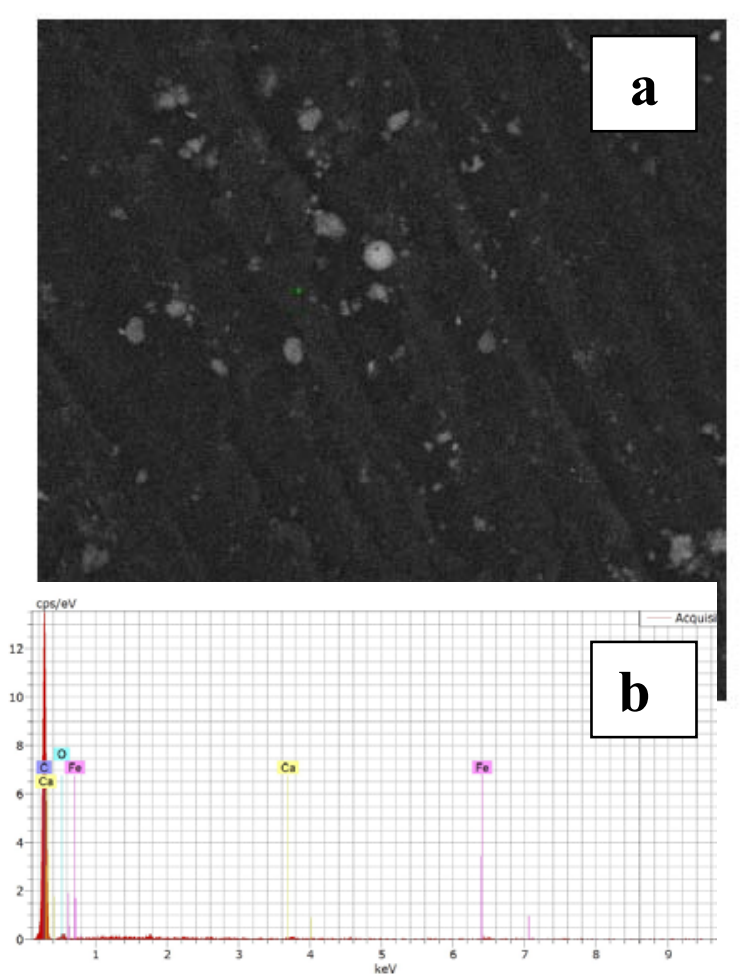

Figure 8, (a) SEM and (b) EDS of the RPP with 30\%IP

\section{Conclusions}

The recycle polypropylene has been used with the iron powder using plastic injection moulding technique and the following conclusions have been obtained:

1 -The results showed that, by adding $10 \%, 20 \%$, and $30 \%$ wt. of iron powder to the recycled polypropylene, the ultimate tensile strength increased from $21 \mathrm{~N} / \mathrm{mm} 2$ for neat recycled polypropylene to $24.828 \mathrm{~N} / \mathrm{mm} 2$ (i.e. $18.23 \%$ ), $26.34 \mathrm{~N} / \mathrm{mm} 2$ (i.e. $25.44 \%$ ), $27.72 \mathrm{~N} / \mathrm{mm} 2$ (i.e. $32 \%$ ), respectively.

2- The modulus of elasticity is increased to 412.06 $\mathrm{MPa}(6.28 \%), 427.4 \mathrm{MPa}(10.259 \%$, and to $566.30 \mathrm{MPa}(46.09 \%)$ when adding IP $10 \%$, $20 \%$, and $30 \%$ wt of IP to the RPP respectively.

3- The wear test results showed that, as the iron powder contents is increased, the weight loss is decreased and the best results is for $10 \%$ iron powder, in which the weight loss is reduced to $43.34 \%, 48.9 \%$, and $54.37 \%$ at $500 \mathrm{~g}, 1000 \mathrm{~g}$, and $1500 \mathrm{~g}$ respectively. 
4- The hardness test results showed that, as the iron powder contents are increased, the hardness are increased from 71 for the RPP to $72.5,75$, and 76 for RPP with iron powder contents of $10 \%, 20 \%$, and $30 \%$ respectively.

5- SEM is used and it can be concluded that, the using of plastic injection moulding process of the RPP and the IP can produce a product of RPP/IP with good distribution of iron powder in the RPP.

\section{REFERENCES}

[1] Erwin Burkle et al, "Injection Moulding of long glass fiber reinforced $\mathrm{pp}^{\prime}$, Translated from Kunststoffe plastic Europe, 3/2003, pp, 47-50

[2] Loredan Incarnato Scarfato and Domenico Acierno, "Rheological and Mechanical Properties of Recycled Polypropylene", Polymer Engineering and Science, April 1999, Vol. 39, No. 4

[3] JL. Acosta, MC. Ojeda, C. del Río, "Effect of conducting fillers on the microstructure and electrical conductivity of thermoplastic polymer composites", Polymer Bulletin 57, 199-206, 2006 DOI 10.1007/s00289-006-0542-2

[4] M. Nikzad, S.H. Masood, I. Sbarski, A. Groth, " Thermo-Mechanical Properties of a Metal-filled Polymer Composite for Fused Deposition Modelling Applications", 5th Australasian Congress on Applied Mechanics, ACAM 10-12 December 2007, Brisbane, Australia

[5] Munir Tas, demır H. O " zkan Gu“ lsoy, "Mechanical Properties of Polymers Filled with Iron Powder ", International Journal of Polymeric Materials, 57:258-265, 2008.

[6] X. L. Chen, C. M Jiao, Y. Wang, "Synergistic effects of iron powder on intumescent flame retardant polypropylene system", eXPRESS Polymer Letters Vol.3, No .6, 2009, 359-365.

[7] Tan Foo Khoon, et al, "Dielectric Properties of.Ni0.2Zn0.8Fe2O4-Polypropylene composites ", American Journal of Applied Sciences 7 (9): 1226-1230, 2010.
[8] M. Nikzad, S.H. Masood, I. Sbarski, "Thermomechanical properties of a highly filled polymeric composites for Fused Deposition Modeling " , Materials and Design 32, 2011 3448-3456.

[9] Segun Mathew Adedayo, Modupe Adeoye Onitiri, "Mechanical Properties of Iron Ore Tailings Filled-Polypropylene Composites", Journal of Minerals and Materials Characterization and Engineering, 2012, 11, 671-678

[10] M.A. Onitiri S.M. Adedayo, "Compressive behaviour of polypropylene filled with iron ore tailings", Journal of Engineering, Design and Technology, Vol. 13 Iss 2 pp. $198-212$, http://dx.doi.org/10.1108/JEDT-12-2012-0056

[11] Alaa A. Abdul-Hamead, Thekra Kasim, and Awattiff A. Mohammed, "Mechanical Properties for Polyester resin Reinforce with Fe Weave Wire ", JAIEM, Volume 3, Issue 7, July 2014

[12] N.Sa'ude, M. Ibrahim, band M. H., Ibrahim, "Mechanical Properties of Highly Filled lronABS Composites in Injection Molding for FDM wire Filament", Materials Science Forum Vols. 773-774 (2014) pp 456-461.

[13] Paragon Plastics Santa Ana, "Material identification Guide" PARAGON PLASTICS

[14] www.boedeker.com/burntest.htm, "how to identify plastic material"

[15] A. B. Backensto , and Hammond, [1968], IRON POWDER METALLURGY, Indiana,

[16] www.pfri.uniri.hr/ bopri/documents/ 04_BP CylinderLiners_000.pdf

[17] Designation: D 638 - 02a, "Standard Test Method for Tensile Properties of Plastics", ASTM D638

[18] Ferdinand P. Beer, E. Russell Johnston, Jr. John T. Dewolf David F. Mazurek, "MECHANICS OF MATERIALS", 6th edition, 2012

[19] Madhukar Vable "MECHANICS OF MATERIALS", $2^{\text {nd }}$ edition, 2012 